University of Wollongong

Research Online

Faculty of Engineering and Information

Faculty of Engineering and Information

Sciences - Papers: Part B

Sciences

2017

\title{
Multifunctional Bi-Layered Tribofilm Generated on Steel Contact Interfaces under High-Temperature Melt Lubrication
}

\author{
Hoang Bach Tran \\ University of Wollongong, hbt943@uowmail.edu.au \\ Anh Kiet Tieu \\ University of Wollongong, ktieu@uow.edu.au \\ Shanhong Wan \\ University of Wollongong, shanhong@uow.edu.au \\ Hongtao Zhu \\ University of Wollongong, hongtao@uow.edu.au \\ David R. G Mitchell \\ University of Wollongong, dmitchel@uow.edu.au
}

See next page for additional authors

Follow this and additional works at: https://ro.uow.edu.au/eispapers1

Part of the Engineering Commons, and the Science and Technology Studies Commons

Research Online is the open access institutional repository for the University of Wollongong. For further information contact the UOW Library: research-pubs@uow.edu.au 


\title{
Multifunctional Bi-Layered Tribofilm Generated on Steel Contact Interfaces under High-Temperature Melt Lubrication
}

\author{
Abstract \\ The extreme state of high friction, severe wear, and oxidation invariably occur in mechanical contacts \\ during high temperature steel processing. The application of lubricant to mitigate the aforementioned \\ hindrances can enhance the process performance effectively. Melt lubricants are regarded as a highly \\ promising class due to their good thermal stability and unique physical chemistry. The present study \\ evaluates tribological responses of an alkaline metal borate on steel tribo-pair at $800{ }^{\circ} \mathrm{C}$ by ball-on-disk \\ testing. It has been found that the borate melt significantly reduces the friction coefficient and the wear \\ loss in accompany with providing excellent oxidation resistance. On the disk, the formation of a bilayered \\ tribofilm dominates synergistic functionalities while the emergence of an ultrafine-grained layer \\ considerably reinforces the interface integrity of the opposing ball. Cross-sectional examinations of the \\ contact interfaces were carried out on both steel counterparts by FIB/STEM. STEM/HAADF-EDS reveal \\ the formation of a boundary film featuring high concentration of $B$ and significant depletion of $O$ \\ superimposed on a Na-rich film on the rubbing disk. On the opposing surface, a chemically complex film \\ consisting of $\mathrm{Na}, \mathrm{Fe}, \mathrm{O}$, amorphous $\mathrm{C}$ and ${ }^{[3]} \mathrm{B}$ which resides on nanograins of iron oxide is evidenced by \\ STEM/EELS-EDS. \\ Disciplines \\ Engineering | Science and Technology Studies

\section{Publication Details} \\ Tran, B. H., Tieu, A. K., Wan, S., Zhu, H., Mitchell, D. R. G. \& Nancarrow, M. J. (2017). Multifunctional Bi- \\ Layered Tribofilm Generated on Steel Contact Interfaces under High-Temperature Melt Lubrication. The \\ Journal of Physical Chemistry C: Energy Conversion and Storage, Optical and Electronic Devices, \\ Interfaces, Nanomaterials, and Hard Matter, 121 (45), 25092-25103.

\section{Authors} \\ Hoang Bach Tran, Anh Kiet Tieu, Shanhong Wan, Hongtao Zhu, David R. G Mitchell, and Mltchell John \\ Bromley Nancarrow
}




\title{
Multifunctional Bi-Layered Tribofilm Generated on
}

\section{Steel Contact Interfaces under High-Temperature Melt}

\section{Lubrication}

\author{
Bach H. Tran ${ }^{1}$, Anh Kiet Tieu ${ }^{1}$, Shanhong Wan ${ }^{1}$, Hongtao Zhu ${ }^{1}$ \\ David R.G. Mitchell ${ }^{2}$, Mitchell J. Nancarrow ${ }^{2}$
}

${ }^{1}$ Faculty of Engineering and Information Sciences,

University of Wollongong, Northfields Avenue, Wollongong, NSW 2522, Australia

${ }^{2}$ Electron Microscopy Centre, University of Wollongong, NSW 2522, Australia

\section{Corresponding Author \\ *Anh Kiet Tieu, ktieu@uowmail.edu.au \\ * Shanhong Wan, shanhong@uow.edu.au}




\section{ABSTRACT:}

The extreme state of high friction, severe wear and oxidation invariably occur in mechanical contacts during high temperature steel processing. The application of lubricant to mitigate the aforementioned hindrances can enhance the process performance effectively. Melt lubricants are regarded as a highly promising class due to their good thermal stability and unique physical chemistry. The present study evaluates tribological responses of alkaline metal borate on steel tribo-pair at $800^{\circ} \mathrm{C}$ by ball-on-disc testing. It has been found that borate melt significantly reduces friction coefficient, wear loss accompanied by excellent oxidation resistance. On the sliding disc, the formation of a bi-layered tribofilm dominates synergistic functionalities while the emergence of an ultrafine-grained layer considerably reinforces the interface integrity of the opposing ball. Cross-sectional examinations of the rubbing interfaces were carried out on both steel counterparts by FIB/STEM. STEM/HAADF-EDS reveal the formation of a boundary film featuring high concentration of $\mathrm{B}$ and significant depletion of $\mathrm{O}$ superimposed on a Na-rich film on the rubbing disc. On the opposing surface, a chemically complex

film consisting of $\mathrm{Na}, \mathrm{Fe}, \mathrm{O}$, amorphous $\mathrm{C}$ and ${ }^{[3]} \mathrm{B}$ residing on nano-grains of iron oxide is evidenced by STEM/EELS-EDS. 


\section{Introduction}

High temperature tribology emerges as a vital research area which delivers immense significances to manufacturing industries, particularly hot metal forming processes. Exposure to extreme temperature and pressure under shearing condition leads to numerous interfacial phenomena which are complex in nature. Apart from classic hindrances of substantial friction and excessive wear, oxidation becomes increasingly severe and simultaneously governs surface tribology at elevated temperature. Thus, there are always pressing needs to alleviate those concerns in order to enhance process productivity and lubrication is considered as an effective approach. However, the fact that lubricant is inevitably affected by the heat factor makes the whole tribology system become exceedingly complicated. Thermal behaviors, chemical reactivity and other relevant properties can play definite roles on the lubrication performance.

There are various types of lubricant employed in hot metal forming (e.g. hot rolling) and oil-based class is among the most popular. Oil droplets are believed to enter the voids between contact asperities and function as friction reducing and cooling agent. However, vulnerability to thermal degradation is speculated to undermine the performance of hydrocarbon-based lubricants. Solid lubricants which are typical 2-dimensional compounds possessing easy-to-shear structure, have been selected widely in practice. Despite behaving promisingly in term of friction reduction and wear reduction, anti-oxidation capacity of solid lubricants remains obscure. Within this category, graphite is a typical representative followed by several candidates such as $\mathrm{MoS}_{2}$, h-BN, metal oxides ${ }^{1} \ldots$ Melt lubricants ${ }^{2}$ are considered as potential alternatives for high temperature lubrication since they possess a desirable set of thermal and chemical characteristics. Inorganic metal oxides (or glass forming compounds) present as the most 
fundamental constitution of melt lubricant. The concept of melt lubrication is based on utilizing molten viscous state of the lubricant induced by thermal transition for tribological purposes.

Organo-polyphosphate is well-known as the most successful lubricant additive in engine oil. A tribologically generated film characterized by glass-like properties is accountable for outstanding performance of the additive. It is conclusively proven that the tribofilm possesses a polymeric nature with desirable reactivity towards abrasive debris which is the foundation for its anti-wear characteristic. Regarding high temperature application, inorganic polyphosphate-based lubricant reportedly gains plenty of attraction. A hierarchical layered structure of the polyphosphate tribofilm governs the interfacial chemistry and exhibits exceptional performance regarding friction reduction, wear inhibition and oxidation resistance ${ }^{3-4}$. Beside phosphate derivatives, it is believed that polymeric melts of boron, silicate can deliver comparative competency. Despite of being studied extensively at moderate temperature ${ }^{5}$, it is still under scrutiny how the B-bearing melt behaves in response to tribological exposure at high temperature, especially interactions between melt elements and the surface material. The present study aims to evaluate tribological properties of an inorganic borate-based lubricant on steel contact at elevated temperature. The investigation determines not only how effectively the melt can perform, but also reveals the local chemical structure of the boundary film and effects of hightemperature oxidation. Microstructure characterizations were carried out on the tribo-interfaces of the steel pair which produce a complete illustration of the whole contact boundary.

\section{Experimental section}

\subsection{Preparation of the aqueous lubricant}

Sodium Tetraborate Decahydrate $\left(\mathrm{Na}_{2} \mathrm{~B}_{4} \mathrm{O}_{7} .10 \mathrm{H}_{2} \mathrm{O}\right)$ was selected for the hot friction test. The chemical was purchased from Sigma-Aldrich and used without further modification. Raman analysis 
was carried out to determine the molecular structure of the compound and the resultant spectrum is given in Figure 1. The sharp peak located at $580 \mathrm{~cm}^{-1}$ is assigned to isolated-diborate which is the predominant structural group in sodium borate ${ }^{6}$. Molecular structure of isolated-diborate unit indicates simultaneous coexistence of triangular $\left(\mathrm{BO}_{3}\right)$ and tetrahedral $\left(\mathrm{BO}_{4}\right)$ boron sites. A definite amount of sodium borate was dissolved into distillated water, forming $5 \%$ wt. solution which was subsequently used in lubrication test.

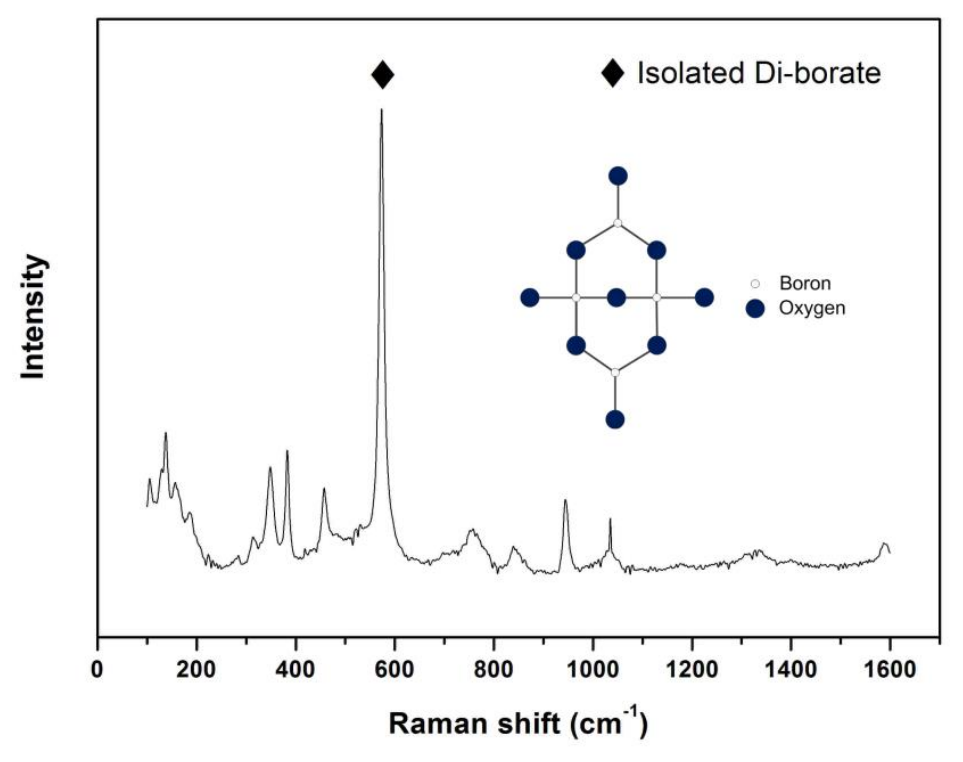

Figure 1: Raman spectrum of inorganic sodium borate with molecular structure of isolated-diborate group.

Transition temperature of sodium borate is determined by mean of High Temperature Microscopy coupled with CCD camera. A mild carbon cuboid substrate $(3 \times 3 \times 2.5 \mathrm{~mm})$ with roughness of $10 \mathrm{~nm}$ was fixed onto a 5mm-diameter alumina crucible. Small amount of lubricant powder was gently located on steel specimen which was subsequently inserted into an ellipsoidal infrared heating furnace. The specimen was then heated by an infrared source to $800^{\circ} \mathrm{C}$ at a rate of $1.5^{\circ} \mathrm{C} / \mathrm{s}$ under Argon atmosphere (99.999\% Ar). The schematic illustration of the testing apparatus is shown in Figure S1. In-situ 
observation of physical state variation was accomplished by continuous recording video through objective lens. By $525^{\circ} \mathrm{C}$, the solid particle gradually transforms from rigid state into a highly viscous liquid (Figure 2), marking the transition point of sodium borate which agrees with previous reports ${ }^{7-8}$. DSC/TGA analysis was further carried out to support the melting behavior of borate (Figure 3). An endothermic peak located at $530^{\circ} \mathrm{C}$ clearly indicates the melting point of the compound.
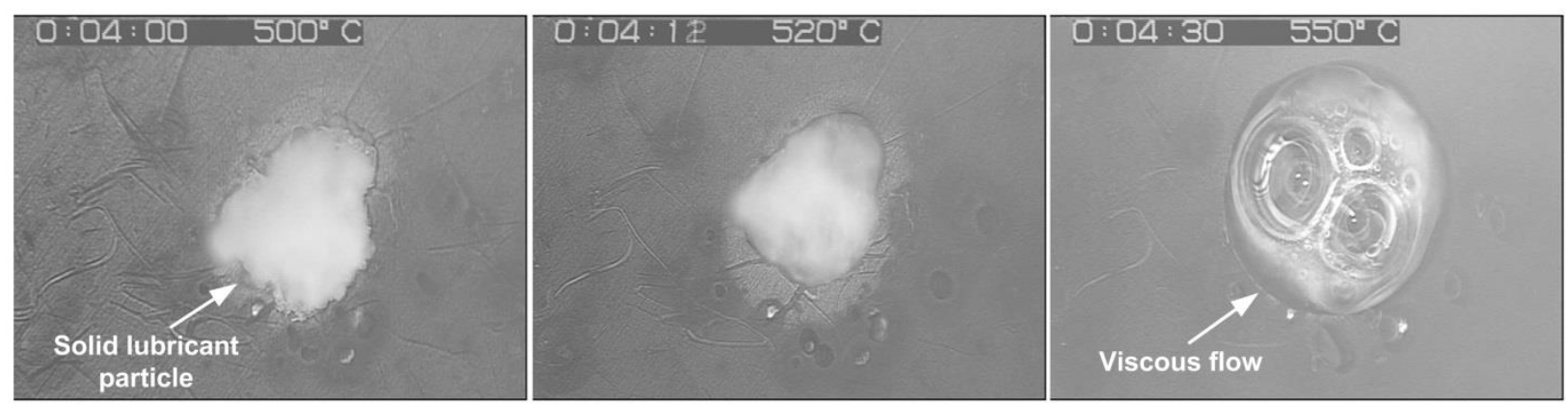

Figure 2: Snapshots of sodium borate particle through its transition point in High Temperature Microscopy.

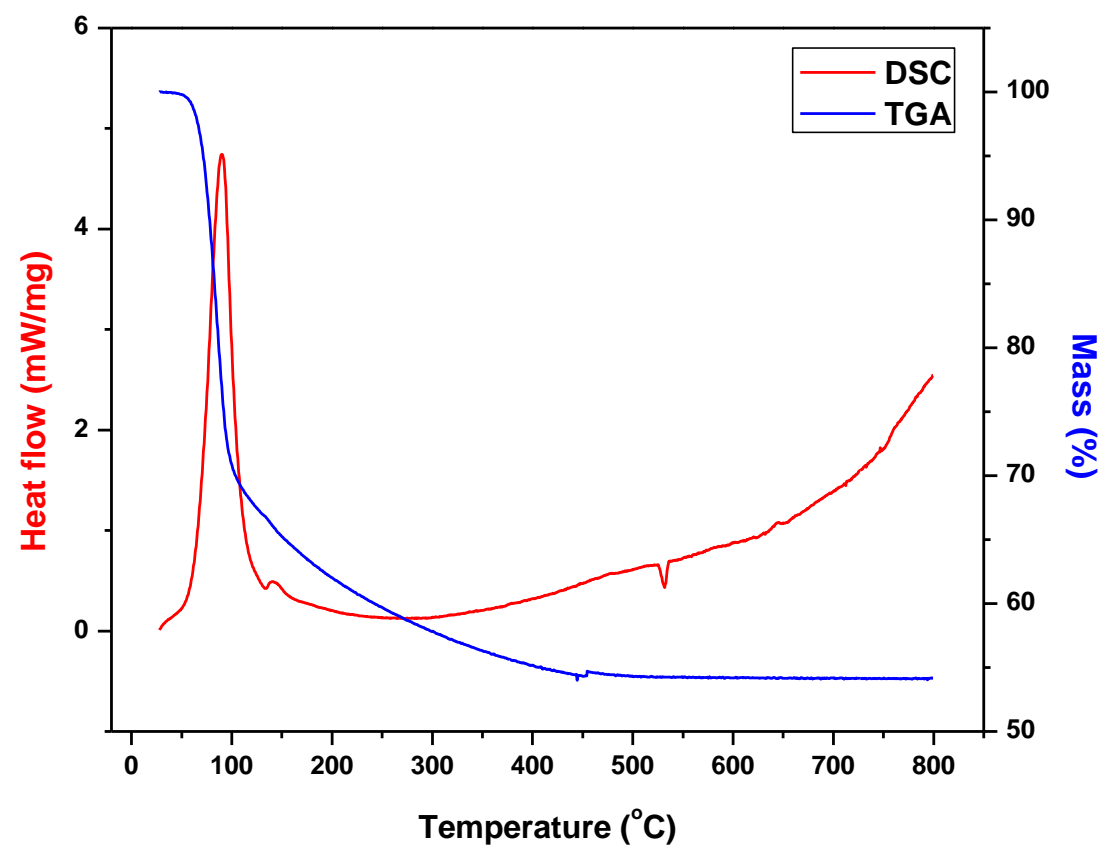

Figure 3: DSC and TGA curves of sodium borate. 


\subsection{Steel samples preparation}

6.35mm-diameter Chromium GCr15 ball (C:Si:Cr:Fe = 0.98:0.35:1.48:balanced-\%wt.) was selected as stationary component with an initial roughness of $\sim 20 \mathrm{~nm}$ and hardness of $60-62 \mathrm{RHC}$. Mild carbon steel $(\sim 0.3 \% \mathrm{C})$ with a hardness of $235 \mathrm{HV}$ was chosen for rotating disc material. The round disc is $3 \mathrm{~mm}$ thick and $50 \mathrm{~mm}$ in diameter, moderately polished to achieve a roughness of $1 \mu \mathrm{m}$. Prior to friction test, both steel components were ultrasonically cleaned by ethanol and acetone respectively for contaminants removal.

\subsection{Friction tests}

Hot friction tests were performed on a UMT2-CETR high temperature ball-on-disc tribometer. Steel counterparts were firstly installed into the tribometer then the furnace was heated to a set temperature. The non-isothermal heating period was divided into multiple sequences to minimize the risk of thermal overshooting. $\mathrm{MC}$ disc rotates at 5rpm during heating stage to ensure homogenous heat distribution while the GCr15 ball is located at $5 \mathrm{~mm}$ above the disc surface. Sliding tests were carried out at $800 \pm 1^{\circ} \mathrm{C}$ while the nominal load was kept at $10 \mathrm{~N}$ with a linear sliding velocity of $0.1 \mathrm{~m} / \mathrm{s}$. In case of dry sliding test, an external thermal couple was embedded into the ball, capable of recording its temperature evolution. Figure S2 shows temperature development of each tribo-component in stabilization and sliding stage. The maximum contact pressure was calculated according to reduced young modulus of the oxide scales at testing temperature, reaching a value around $0.72 \mathrm{GPa}^{9}$. The sliding duration is 5 minutes, the tribopairs were immediately retrieved and cooled in air after each test to prevent further oxidation. During the lubrication tests, lubricant solution was fed onto the rotating disc with a dropping rate of $0.01 \mathrm{ml} / \mathrm{s}$ through an external monitor. The onset of lubricant introduction is 2 minutes before contact engagement. Friction coefficient was acquired via an integrated computer system for the whole sliding period. Reproducibility was ensured by a number of repetitive tests. 


\subsection{Characterization}

The structure of sodium borate was investigated by using Raman scattering. A JY HR800 Raman spectrometer with 3um spot size and 1065nm laser line was used on the powdered lubricant. An X-ray diffraction (XRD) using GBC MMA diffractometer with mono-chromated $\mathrm{Cu}-\mathrm{K} \alpha$ radiation was used to examine the phase composition of wear debris produced from dry sliding test. The operating voltage and current of the X-ray beam was selected at $35 \mathrm{kV}$ and $28.6 \mathrm{~mA}$, respectively. Thermal analysis of borate was carried out using a Differential Scanning Calorimetry (NETZSCH STA 449DSC) under Nitrogen atmosphere at a heating rate of $10^{\circ} \mathrm{C} / \mathrm{min}$.

After friction test, morphologies of worn surfaces were examined by a JOEL JSM-6490LV Scanning Electron Microscopy (SEM) coupled with Energy Dispersive Spectroscopy (EDS). Low accelerating voltage $(5 \mathrm{keV})$ was employed to extract topographies and chemical composition from the near-surface region while working distance was maintained at $10 \mathrm{~mm}$. In case of lubrication test, steel counterparts were carefully washed in distilled water multiple times before volume loss measurement. Ball loss volume was calculated from the worn scar dimension while the according figure was measured by a Stylus Profiler (Dektak 150 Surface Profilometer) on the wear track.

In order to prepare cross-sectional specimens for STEM observation, thin lamellars were produced by a Dual Beam FEI Helios NanoLab G3 CX using Gallium ion source. The areas of interest were chosen perpendicular to sliding direction on both steel counterparts. Prior to target sectioning, a thin layer of $\mathrm{Pt}$ was deposited for extra protection. By employing various fine beam currents (minimum $\sim 1.1$ na) at the finishing steps, the lamellar is adequately thinned to extract the interface crystallography and be viable for STEM-EELS characterization. Specimens were constantly kept under high vacuum atmosphere in the instrument until STEM session to avoid undesired pollution/oxidation. Thin foils carrying tribointerface were observed by an aberration-corrected JOEL ARM 200F Scanning Transmission Electron 
Microscopy (STEM). At $200 \mathrm{kV}$, the microscopy features a large area SDD EDS detector allowing elemental mapping with atomic resolution of the tribofilm. Coupled with a Gaitan GIF quantum spectrometer, the JOEL-ARM 2000 AFM is able to perform Electron Energy Loss Spectroscopy (EELS). Energy-loss edges can be referred to the fine structure and probable oxidation number of specific elements. EELS analysis was operated at 10 order of magnitude lower than STEM mode to mitigate radiation damage with beam dispersion of $0.1 \mathrm{eV}$. A series of spectrum was extracted from Spectrum Images covering a certain Region of Interest (ROI). The spectra underwent backgroundsubtraction by fitting the pre-edge to a power function law $\mathrm{AE}^{-\mathrm{r}}$, where $\mathrm{E}$ is the energy loss and $\mathrm{A}$ and $\mathrm{r}$ are constants. X-ray analysis was performed using NORAN System X-ray Analysis with functional EDS mapping routines. In phase mapping, X-ray spectrum is automatically inspected and compared at every single pixel from spectral image. By using a proprietary algorithm, pixels with statistical similarity are grouped together corresponding to specific phases.

Transmission images were captured using Bright Field (BF) and High Angle Annular Dark Field (HAADF) detector simultaneously. Since the lubricant melt is formulated of Boron which is typically a light element, detection of such component is restricted by the low yield of X-ray signal. This could be due to either high accelerating voltage or negligible sample thickness which results in poor X-ray generation and detection. In an attempt to overcome the rising issue, high-angle annular dark field (HAADF) imaging is employed. Based on Rutherford scattering, collected signal from high-angle incoherent electrons is heavily dependent on atomic number $\left(\mathrm{Z}^{2}\right)^{10}$ of the element. Therefore, STEMHAADF images can exhibit high sensitivity toward compositional contrast (given negligible lamellar thickness deviation) and were already used in various applications to differentiate elements with $\mathrm{Z}$ disparity $^{11-12}$. In general term, high-Z atoms with higher diffraction ability will generate greater 
brightness in comparison to light elements. In the present study, combination of HAADF and STEMEDS was utilized to justify the distribution of low-Z Boron in the tribofilm generated on the wear track.

\section{Results}

\subsection{Friction and wear behavior of steel contacts at elevated temperatures}

Friction coefficient curves of unlubricated and lubricated friction tests (at $800^{\circ} \mathrm{C}, 10 \mathrm{~N}, 0.1 \mathrm{~m} / \mathrm{s}$ ) are illustrated in Figure 4. It can be seen that characteristically high friction coefficient is yielded in case of dry sliding $(\sim 0.42)$ which has been acknowledged in previous report ${ }^{3}$. In stark contrast, the introduction of molten sodium borate leads to a dramatic decline in friction coefficient $(\sim 0.18)$ by approximately $58 \%$ compared to unlubricated condition. Thorough the entire lubrication test, the melt lubricant shows a steady and rapid response to sheared stress condition initiated by a 50 -second running-in period. The according wear loss volumes of the tribo-pairs in unlubricated/lubricated condition are shown in Figure 5. In case of dry sliding test, worn loss volumes were recorded at $5,01.10^{-2} \mathrm{~mm}^{3}$ and $2,44 \mathrm{~mm}^{3}$ on the ball and the disc, respectively. The corresponding figures experienced substantial drop on both steel counterparts when exposed to the melt lubrication. On the ball, the volume loss is five-fold lower than that produced in unlubricated condition, reaching roughly $1.10^{-2} \mathrm{~mm}^{3}$ while the degree of wear reduction registers at remarkably $\sim 95 \%$ on the opposing disc. It is evident that borate melt exhibits excellent lubrication performances regarding friction reduction and wear reduction for coupled steel contacts at $800^{\circ} \mathrm{C}$. 


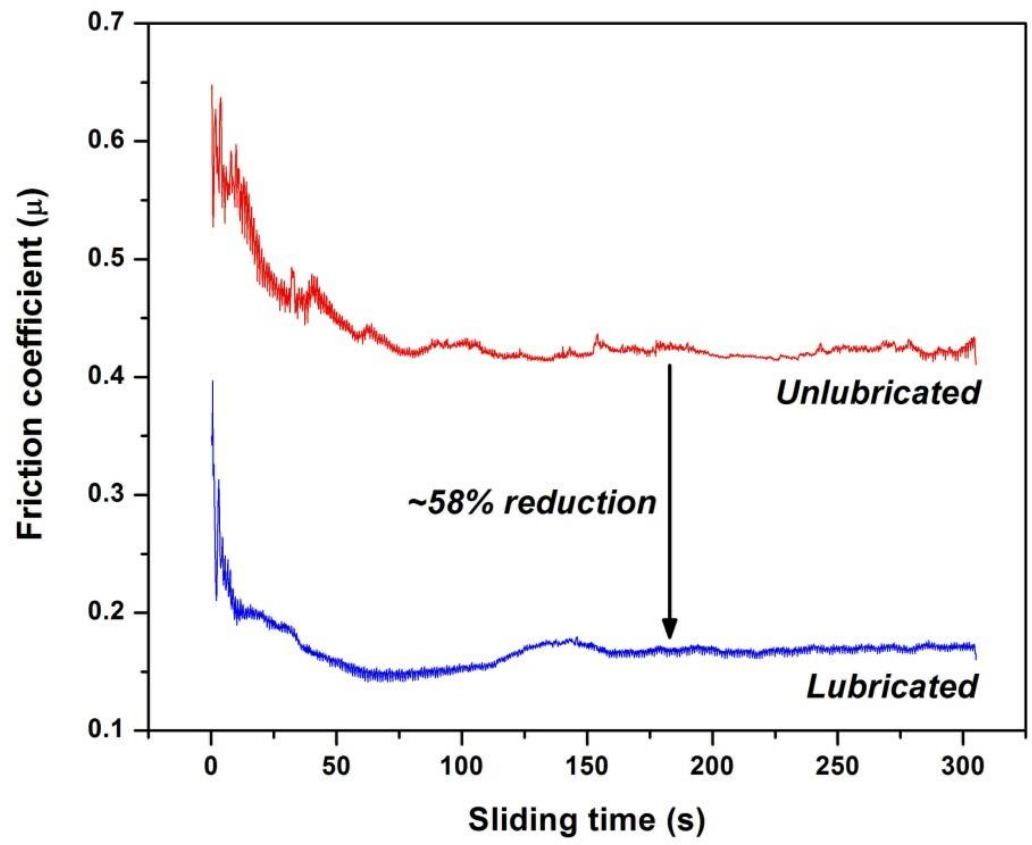

Figure 4: Friction coefficient evolution of unlubricated and melt-lubricated steel tribo-pair (at $800^{\circ} \mathrm{C}$, nominal load of $10 \mathrm{~N}, 0.1 \mathrm{~m} / \mathrm{s}$ ).

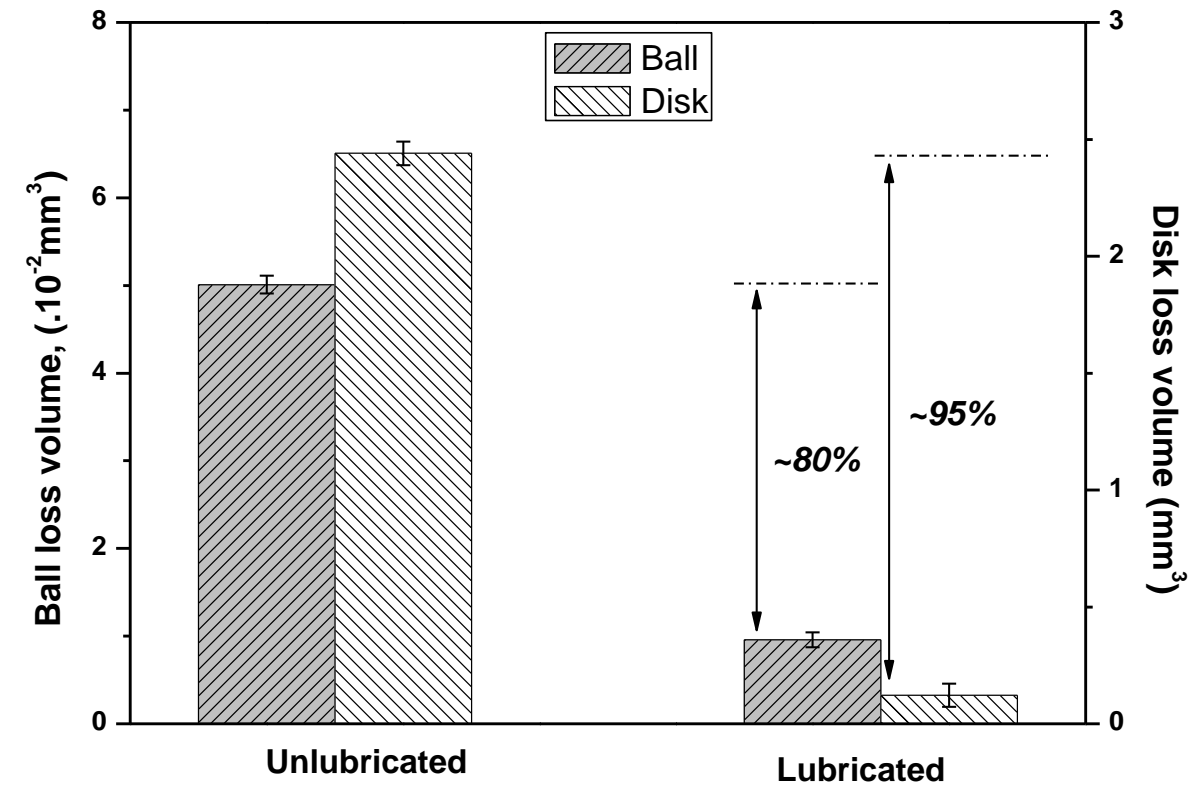

Figure 5: Wear loss volumes of unlubricated and melt-lubricated steel tribo-pair (at $800^{\circ} \mathrm{C}$, nominal load of $10 \mathrm{~N}, 0.1 \mathrm{~m} / \mathrm{s}$ ). 
After dry sliding test, worn surface morphologies of steel tribo-pair are shown in Figure 6. Micrograph of the ball scar shows a variety of superficial damages such as microgrooves, ploughing and plastic smearing (Figure 6a). Across the worn area, a substantial amount of wear debris can be observed which potentially act as a third-body abrasive source. Likewise, the wear track is moderately grooved parallel to sliding direction and featured with dominant iron oxides debris. Magnified zone (Figure 6b) displays a continuous and relatively smooth patch interrupted by multiple shattered fragments. This can be attributed to the dynamic formation of a compact surface glaze which is originated from sheared stress-induced agglomeration of oxides debris. Some believed that the protective glaze layer can provide a certain role in wear resistance ${ }^{13-14}$. Under extreme temperature and oxygen availability, the oxidation of abrasive oxide is spontaneous, leading to the formation of haematite $\left(\mathrm{Fe}_{2} \mathrm{O}_{3}\right)$ which is the hardest among 3 types of iron oxide ${ }^{15}$. The abrasive haematite is considered as the main component causing severe fractures on both rubbing surface. It is further evidenced by the X-ray diffraction of debris oxides (in Figure S3) where haematite $\left(\mathrm{Fe}_{2} \mathrm{O}_{3}\right)$ accounts for the most majority in accompany with a small fraction of magnetite $\left(\mathrm{Fe}_{3} \mathrm{O}_{4}\right)$. EDS spectra of magnified zones also indicate the predominance of $\mathrm{O}$ and $\mathrm{Fe}$ on the worn surfaces of mating counterparts. The pattern similarity suggests the occurrence of adhesive wear where oxide debris was adhered and plastically deformed on the ball. At elevated temperature, it can be deduced that direct sliding contact of steel pairs is characterized by a severe state of abrasive/adhesive wear and plastic deformation which result in high friction and massive materials loss. 
a)
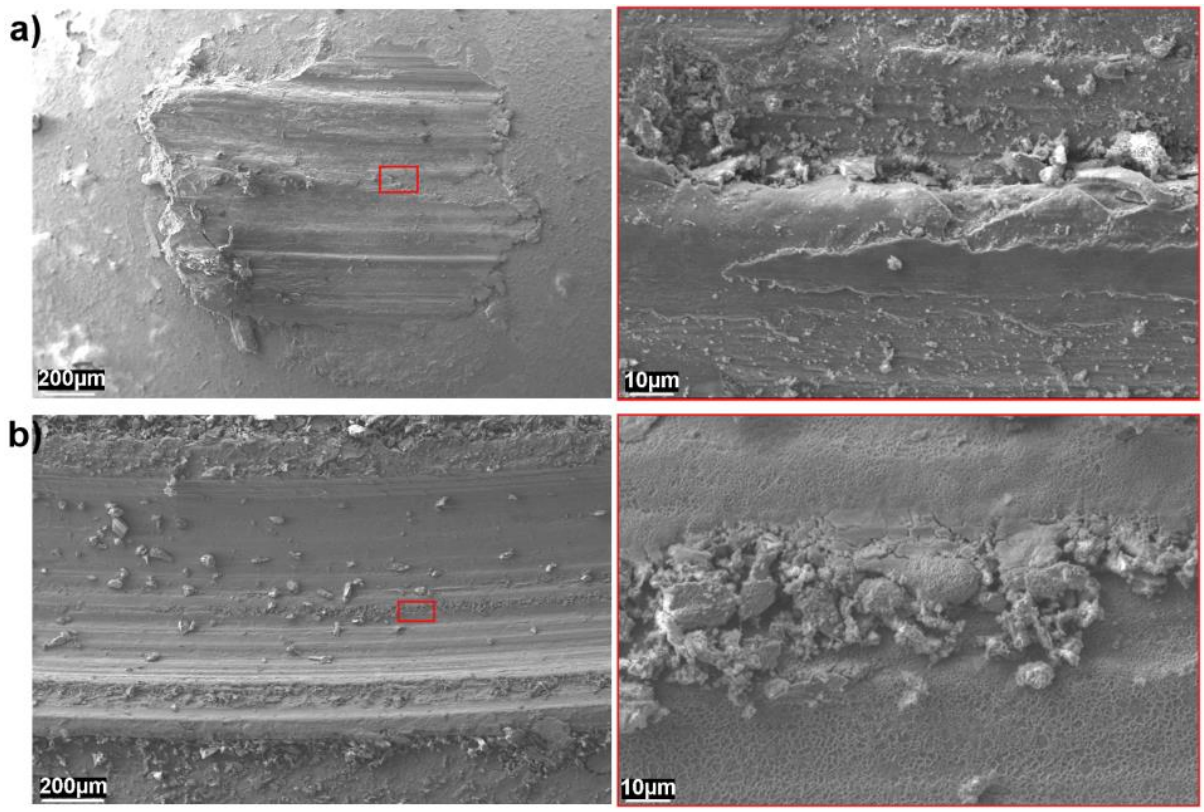
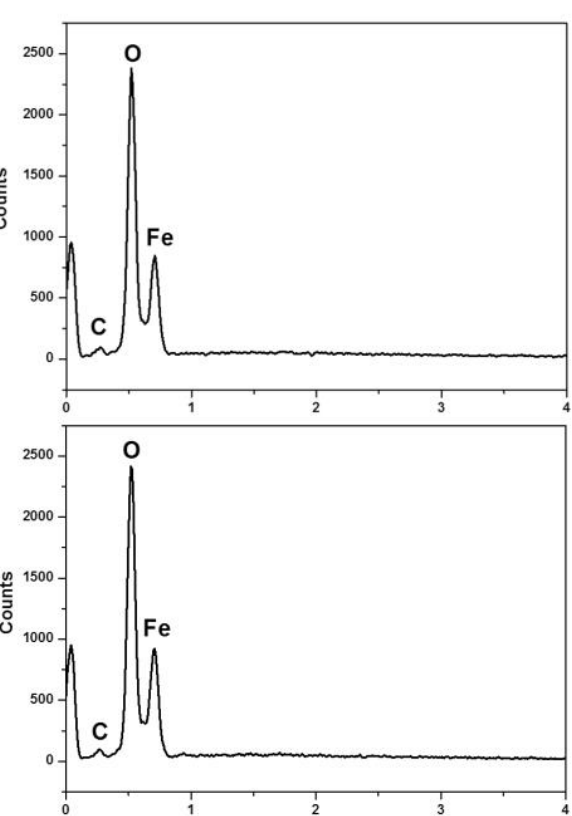

Figure 6: SEM micrographs of the worn surfaces and the according X-ray spectrum after dry sliding test a) ball, b) disc.

SEM micrographs of steel tribo-pair lubricated by borate melt are shown in Figure 7. Highmagnification image (Figure 7b) displays featureless morphology on the wear track except hexagonal platelets residing on a smooth and glassy surface. Those micro-platelets could be the products of melt recrystallization upon cooling. Across the worn scar (Figure 7a), island-like patches can be observed although it is unclear if they represent the actual textures of the contact area. X-ray analysis points out the expected lubricant elements $(\mathrm{B}, \mathrm{Na}$ and $\mathrm{O})$ on the contact surfaces with relatively weak signal from Fe which explicitly implies the presence of a relatively thick film of excessive melt overlying the worn area. Since the borate melt remains viscous ${ }^{16}$ after the friction test, there are possibilities that the molten lubricant moved back onto the worn area and visually masked the intrinsic rubbing interface. The cooled melt itself transforms into glassy solid whose appearance is clearly not correlated to the interface morphologies induced by friction action. The post-friction phenomena of the lubricant melt are not within scopes of the current study. In this case, low-accelerating voltage (5keV) SEM was 
employed to limit the X-ray interaction volume within the bulk sample, thus near-surface compositional information can be extracted. In order to unfold the true interface which holds the essences of intermolecular reactions in the boundary region, cross-sectional observations were conducted by FIB/STEM and discussed in the following sections.
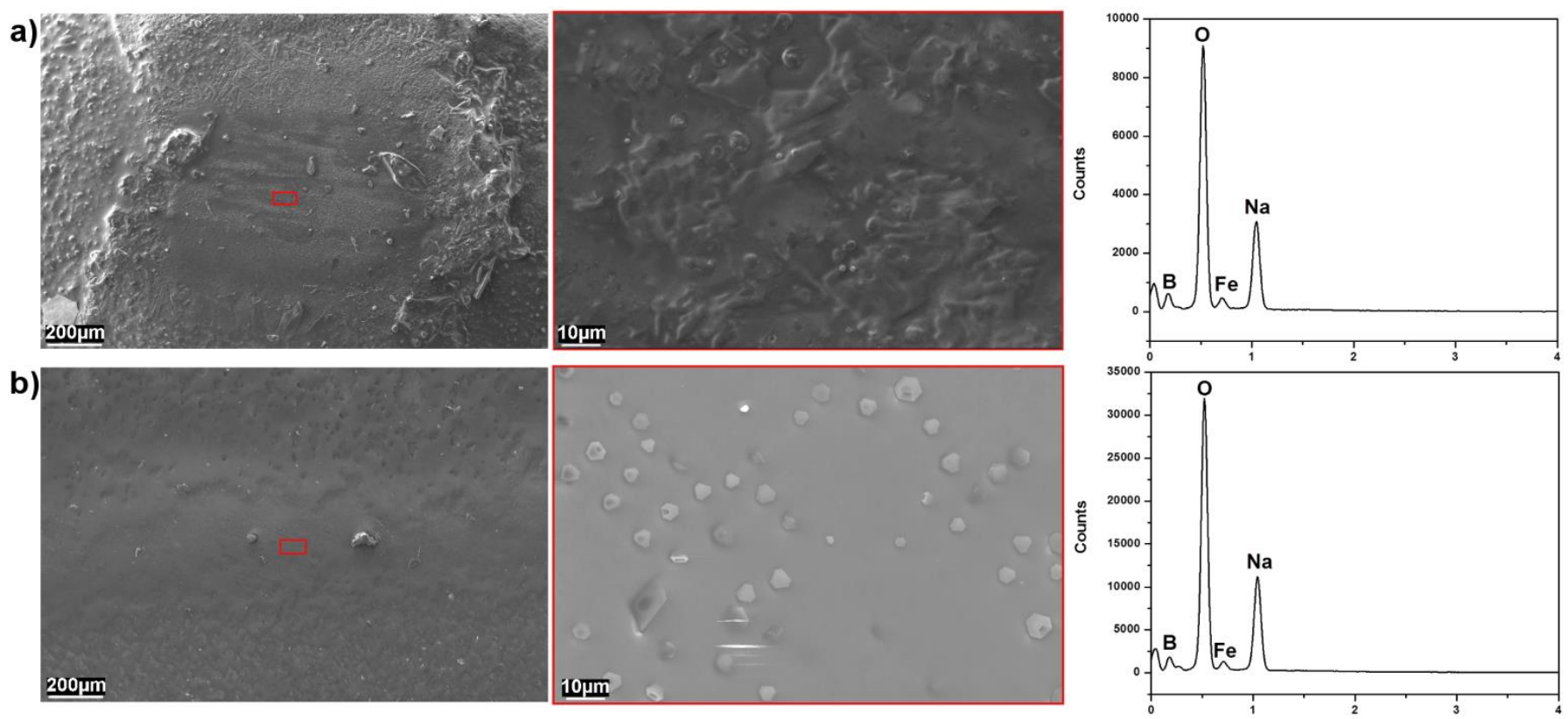

Figure 7: SEM micrographs of melt-lubricated steel components and the according X-ray spectrum after friction test a) ball, b) disc.

\subsection{Tribo-interface generated on the ball}

SEM image of the whole thin lamellar $(12 \mu \mathrm{mx} 8 \mu \mathrm{m})$ extracted from ball scar lubricated by borate melt is given in Figure S4. As suggested from the top-view EDS analysis on the ball scar, it is justified that the interface is covered by an amorphous film with a thickness of $4-5 \mu \mathrm{m}$. The coarse and defectfree debris floating in the residual bulk could be originated from the initial stage when the tribofilm was not yet formed, scattered out of the track and then flew back in the end. Cross-section area was selected perpendicular to the sliding direction to avoid picking up unrepresentative trenches. It can be seen that the tribologically-induced interface appears atonishingly smooth over the region of interest without any 
sign of groove (Figure S4). High-magnified BF image of the ball interface is given in Figure 8a, displaying an interfacial ultra-fine grained region overlying coarser grain basement. The nanolayer is explicitly comprised of iron oxide grains with average size of $50-150 \mathrm{~nm}$ whereas the confinement range is $200-300 \mathrm{~nm}$ from the interface boundary. Popularly known for its intrinsically peculiar mechanical properties, the interface-controlled nanolayer can play a significant role in surface characteristics during the sliding contact. By applying Hurst filter to increase textural differences in course of grey scales ${ }^{17}$, the ultrafine oxide grains are clearly imaged in Figure $8 \mathrm{~b}$.

EDS phase mappings of the ball interface are illustrated in Figure 9 where 3 Phases are distinguished with varying chemical composition. It is obvious that Phase 1 with the predominant composition of Fe and $\mathrm{O}$, is attributed to the grown oxides scale of the steel ball. Phase 2 can be assigned to the residual melt which is composed of mainly $\mathrm{Na}, \mathrm{O}$ and $\mathrm{B}$. It is noted that being a light element makes $\mathrm{B}$ less sensitive to X-ray analysis, thus the signal yield is consequently limited. Accounted for the least area, Phase 3 distributes itself on the boundary region between Phase 1 and Phase 2 with an estimated thickness of $10-20 \mathrm{~nm}$. The interfacial film runs along outer boundary of ultrafine grains layer and consists of $\mathrm{Na}, \mathrm{O}, \mathrm{Fe}, \mathrm{C}$ and possibly B. EELS characterizations were conducted across the interface region to determine the chemical fingerprints of B-K edge and C-K edge, the resultant spectra and that of the melt reference are shown in Figure 10. 

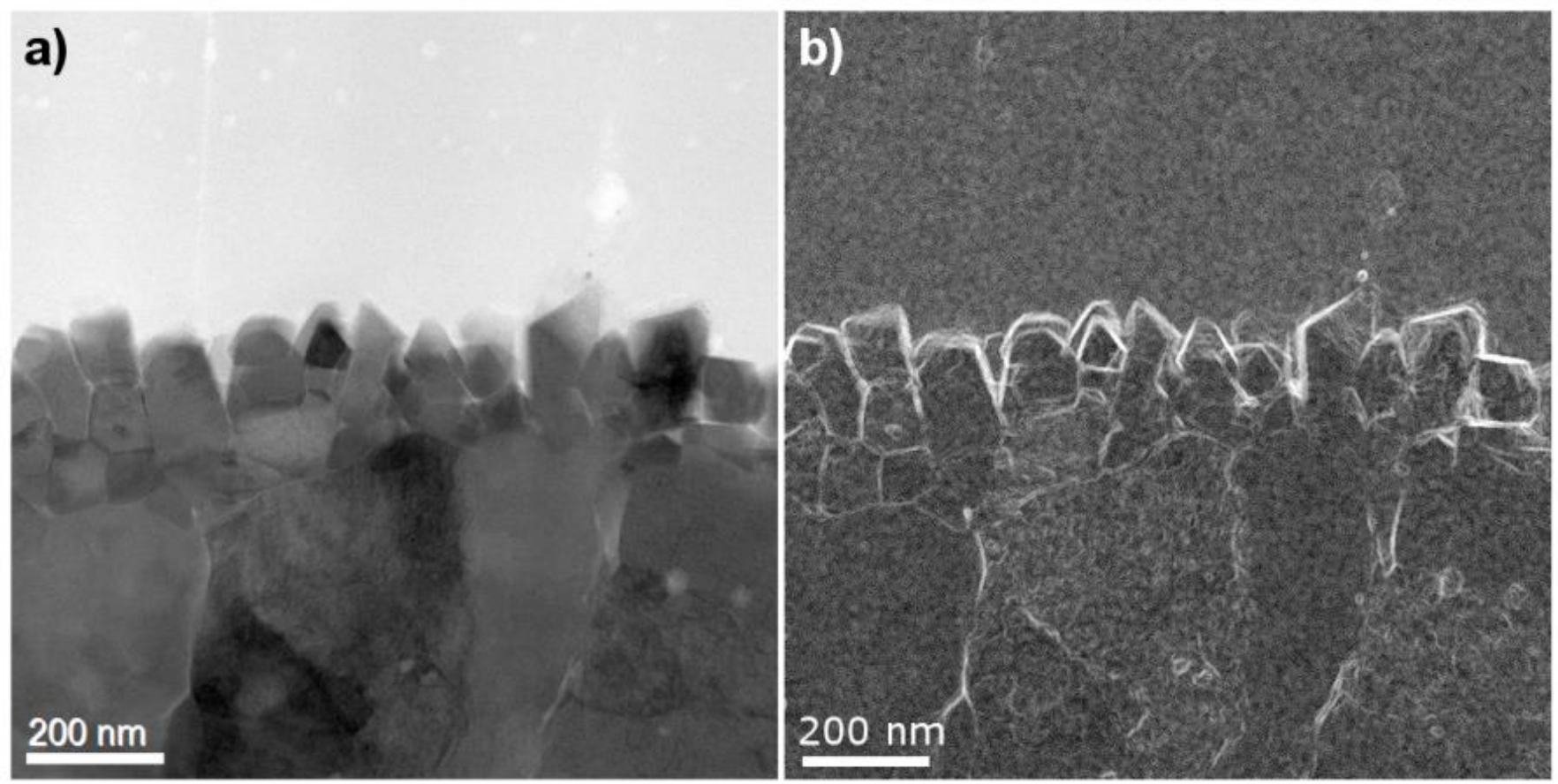

Figure 8: a) Bright Field (BF) image from the GCr15 ball interface lubricated by borate melt, b) application of Hurst filter underlining the nano-grained interface. 

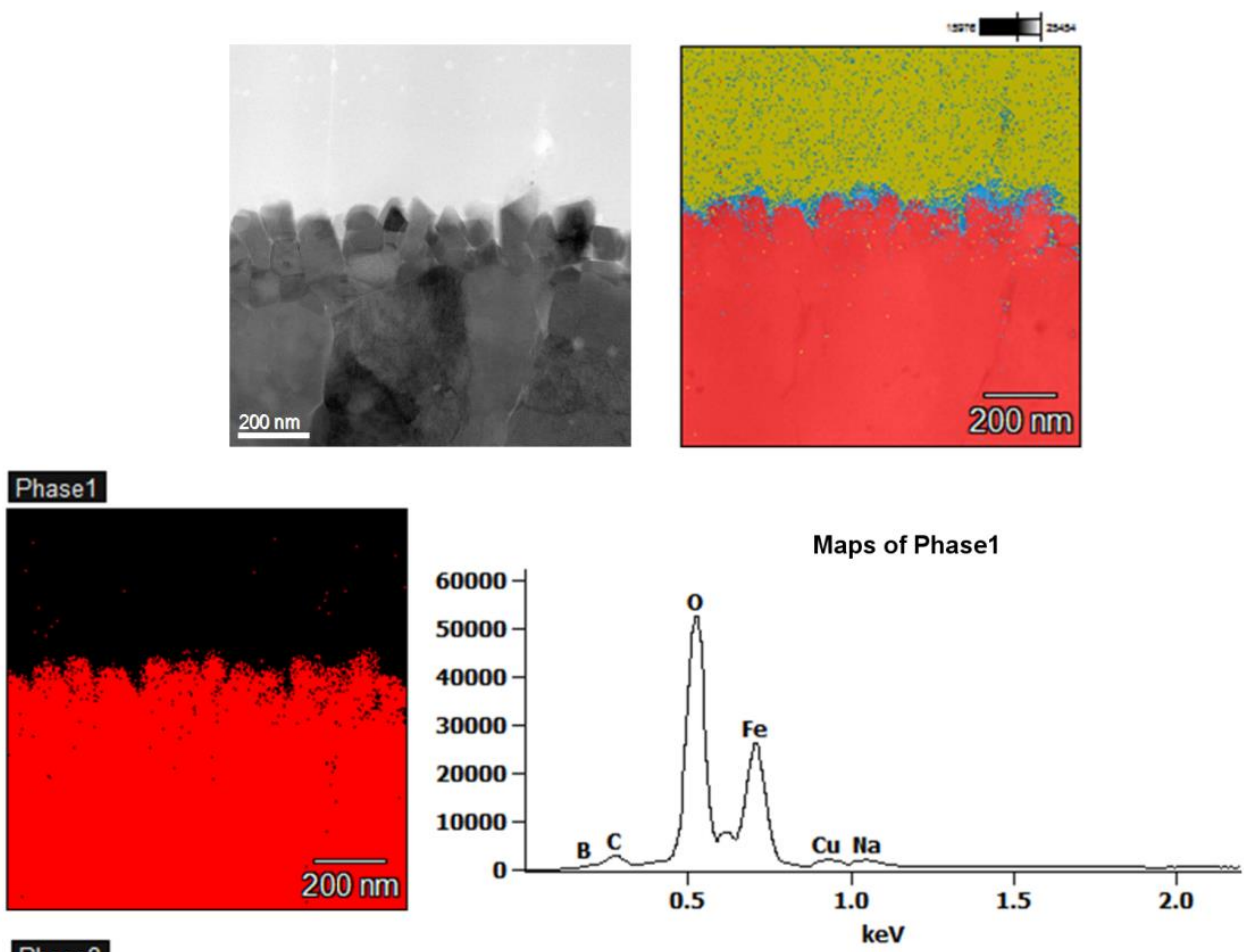

\section{Phase2}
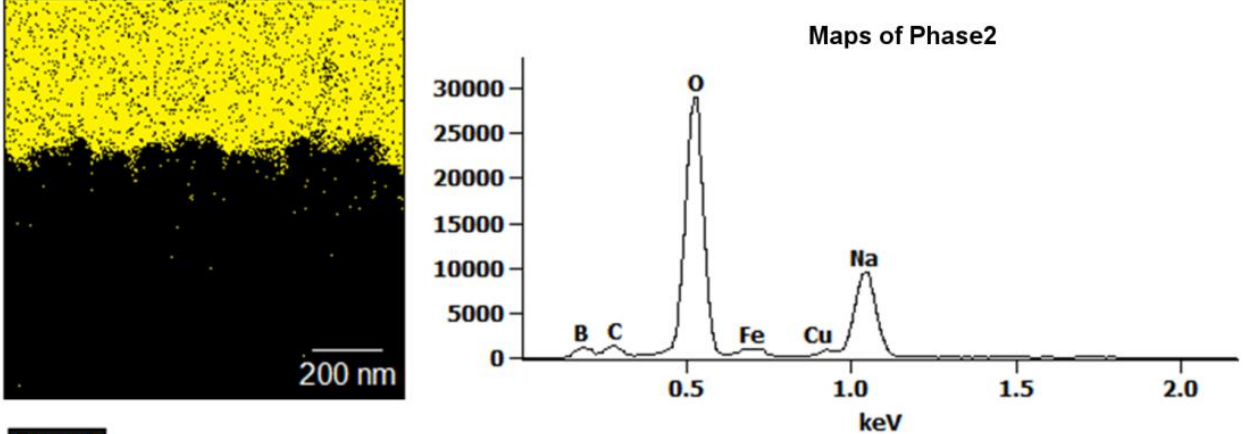

\section{Phase3}
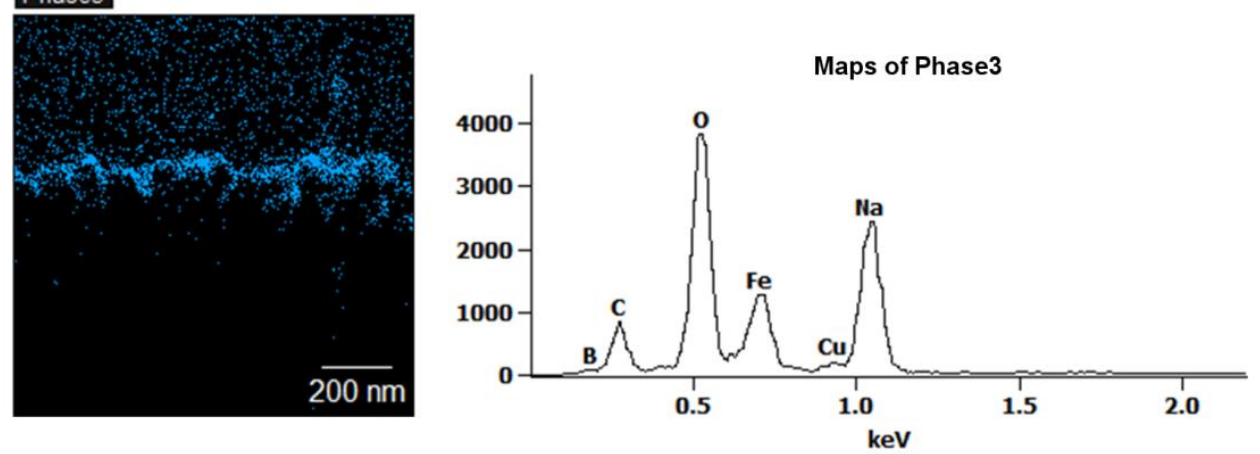

Figure 9: EDS phase mapping with according composition spectra of the ball interface. 

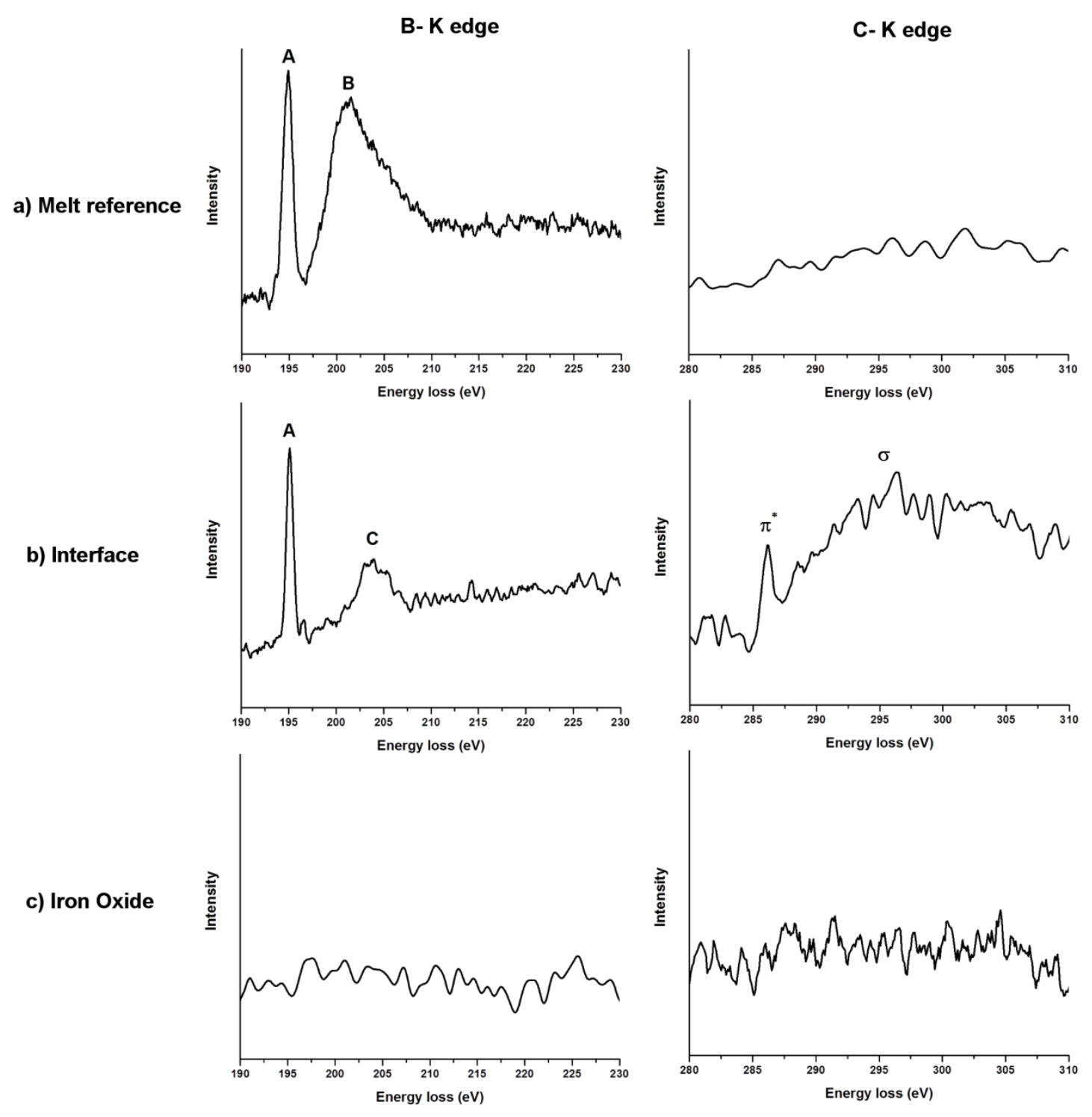

Figure 10: Extracted EELS spectra of $B-K$ edge and $C-K$ edge from a) melt reference, b) interfacial film (Phase III) and c) iron oxide.

The fine structure of B-K edge have been previously resolved with characteristic peaks referring to 2 different configurations of $\mathrm{BO}_{3}$ and $\mathrm{BO}_{4}$ by means of EELS ${ }^{18-19}$. The intense $\pi^{*}$ peak at $194 \mathrm{eV}$ corresponds to the transition of $1 \mathrm{~s}$ electron to unoccupied $\mathrm{p}_{z}$ orbital which defines trigonal ${ }^{[3]} \mathrm{B}$ units, whereas $\sigma^{*}$ peak at $198.6 \mathrm{eV}$ typically represents tetrahedral ${ }^{[4]} \mathrm{B}$ units. Peak located $204 \mathrm{eV}$ is mainly associated to three-fold coordinated ${ }^{[3]} \mathrm{B}$. It can be expected that spectrum from the oxide base without 
the inclusion of Boron and Carbon, reveals no sign of excitation edge from the elements (Figure 10c). The melt reference spectrum displays a sharp peak A located at $194.8 \mathrm{eV}$ followed by a broad hump B with maximum intensity at $202 \mathrm{eV}$ (Figure 10a). The spectrum shape provides strong indication about the co-existence of trigonal ${ }^{[3]} \mathrm{B}$ and tetrahedral ${ }^{[4]} \mathrm{B}$ in the structure of alkali borate glass which is consistent with past studies ${ }^{20-21}$. In contrast, the spectrum extracted from interfacial film (phase 2) shows an intense peak $\mathrm{A}$ at $194.8 \mathrm{eV}$ followed by a broad peak $\mathrm{C}$ at $204.2 \mathrm{eV}$, implying the predominance of plannar $\mathrm{BO}_{3}$ within the film compound (Figure 10b). The conversion from ${ }^{[4]} \mathrm{B}$ to ${ }^{[3]} \mathrm{B}$ could be resulted from effect of sheared stress and complex chemical makeup of the interfacial film. Regarding $\mathrm{C}$, the resultant spectrum from the interface suggests the formation of amorphous carbon while according spectrum is featureless in the melt reference. The peak located at $286 \mathrm{eV}$ is due to the transitions from core $1 \mathrm{~s}$ state to the $\pi^{*}$ state followed by a broad peak which is associated to the transition from $1 \mathrm{~s}$ to $\sigma^{*} \operatorname{state}^{22-23}$. It is noted that spikey appearance might be due to partial radiation damages despite reduced operating voltage in STEM-EELS mode.

\subsection{Tribo-interfacial film generated on the disc}

Thin lamellar $(9 \mu \mathrm{mx} 6 \mu \mathrm{m})$ carrying tribo-interface of the disc is given in Figure S6 and the rubbing surface appears rougher than that on the opposing ball. A relatively thick layer of residual melt $(2-3 \mu \mathrm{m})$ can be observed in agreement with previous claim. Figure 11 illustrates a BF image of the disc interface with the according EDS mapping. Formation of tribologically-generated film can be seen as a continuous and homogenous layer with an approximated thickness of 50-60nm. Close examination suggests that the tribofilm appears to consist of structural layers which can be distinguished by contrast difference. Elemental mapping of Fe and melt compositions (except B) are provided to determine their distributions across the tribofilm. Fe is predominantly found in the scale substrate while there is no sign of its inclusion in the tribofilm as well as the residual melt. Apart from homogenous distribution among 
the residual melt, it is clear that $\mathrm{Na}$ highly concentrates onto the lower region of the tribofilm. On top of that, it is among the most notable that $\mathrm{O}$ is significantly deprived in the tribofilm bulk in comparison to both residual melt and the underlying oxide scale.
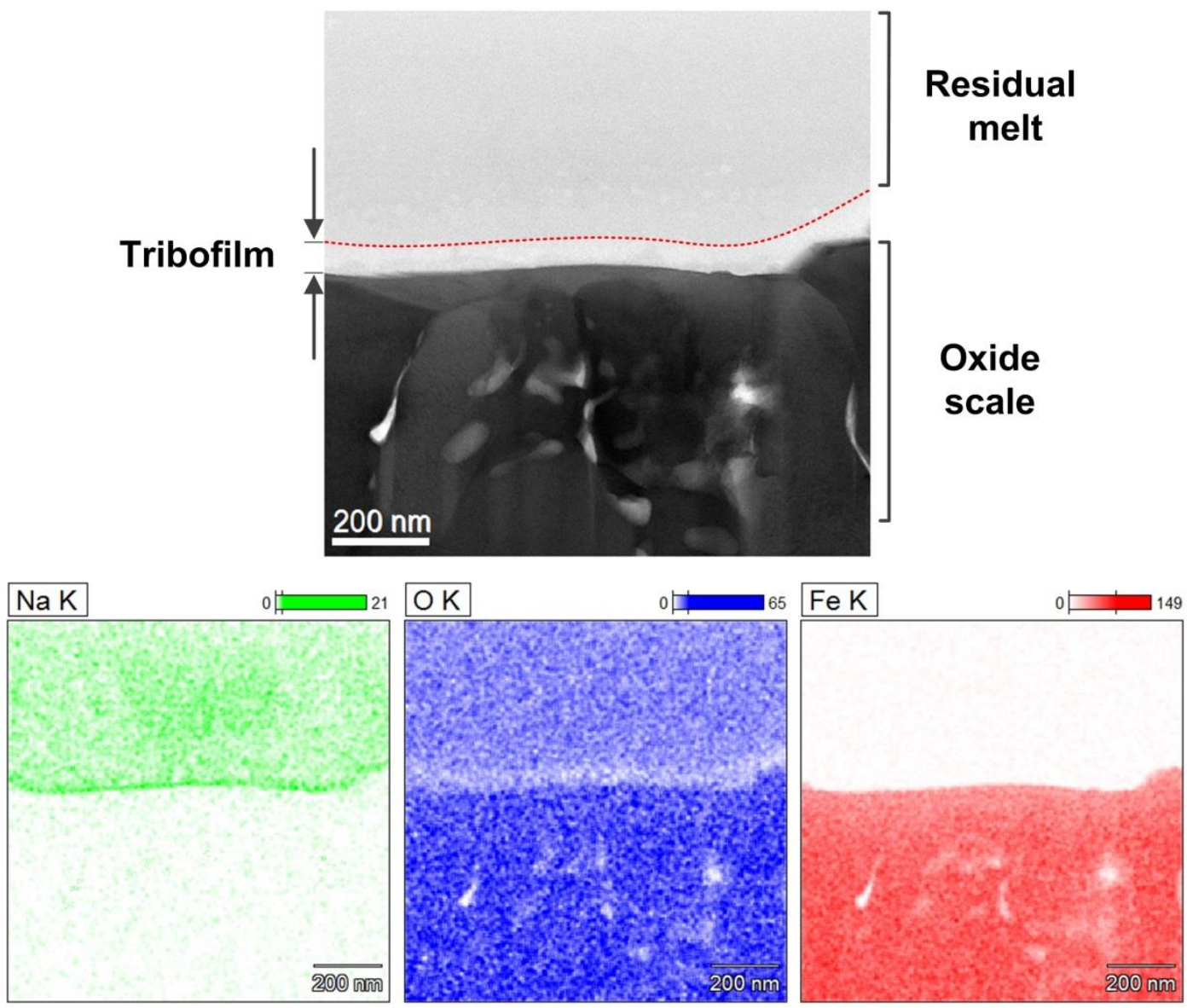

Figure 11: BF image of the tribofilm generated on the ball and the corresponding EDS mapping.

In order to visually underline the layered structure of the induced tribofilm, HAADF imaging technique was employed and shown in Figure 12a. Apart from boundary region, the residual melt presumably contains homogenous composition from point to point, exhibiting uniform contrast. However, clear formation of a bi-layered tribofilm can be observed on the oxide scale (Figure 12b) where the upper layer (II) appears darker than the underlying counterpart (I). In accordance to EDS mapping, it can be deduced that the bottom layer corresponds to the Na-rich region. In addition, it is 
very likely that the top layer is composed of highly-concentrated light elements characterized by its stark contrast compared to the remaining regions. Based on the technique principle, the contrast disparity not only suggests compositional differences but also indicates relative concentration gradient of heavy/light elements. A representative EDS line scan is given to determine intensity profile across the boundary film of $\mathrm{O}, \mathrm{Na}$ and $\mathrm{Fe}$ (Figure 12c). It can be seen that $\mathrm{O}$ is significantly depleted within the tribofilm bulk whereas the intensity of Na suddenly increases followed by an abrupt drop when it comes to the oxide substrate. By the combination of EDS and HAADF imaging, the local chemical structure of the bi-layered tribofilm can be revealed and discussed in details in the following section.
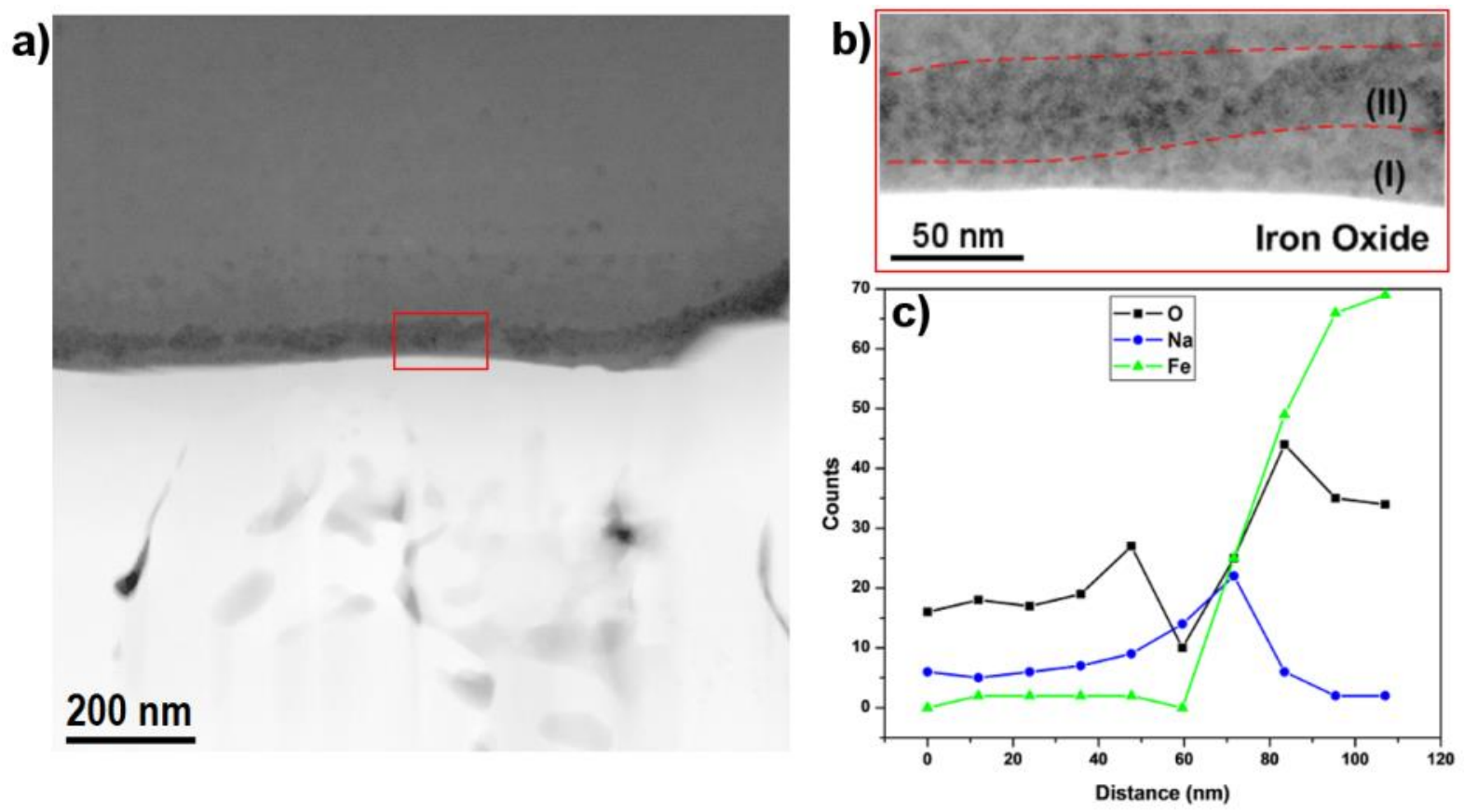

Figure 12: HAADF image of the tribo-interface generated on the disc (a), detailed image of the dual-layered structure (b) and EDS line scan across the tribofilm (c).

\section{Discussions}

The present study revealed excellent lubrication properties of inorganic sodium borate on steel contacts at elevated temperature $\left(800^{\circ} \mathrm{C}\right)$. In order to understand the underlying mechanism of melt 
lubrication, physical chemistry of the molten inorganic poly-oxides deserves consideration. In the molecular structure of sodium borate, there are covalent bonding and ionic bonding that simultaneously coexist: the former one is predominantly attributed to B-O linkage in network formers while the latter refers to modifier interaction O-Na. Upon rising temperature, instead of having a definite melting point, the compound rather transition from a rigid state into a highly viscous liquid. The melt viscosity drops progressively with temperature which is associated to the gradual breakdown of large anionic segments within the glassy network ${ }^{24}$. Eventually, the resultant vitreous melt is characterized by the formation of charged individuals: cationic $\mathrm{Na}$ and anionic B-containing units (predominantly $\mathrm{BO}_{3}{ }^{3-}$ ). The ionic disassociation has been previously proven by the increasing conductivity at the molten state of inorganic oxides by electric measurement ${ }^{24-25}$. The lubricant melt thus could be considered as high temperature ionic liquid whose nature presumably dictates tribological responses involving interfacial reactions and ionic moieties movements. In the friction test, water is only seen as a medium carrier which facilitates lubricant feeding.

As illustrated in the TEM images, there appears an amorphous bi-layered tribofilm generated on the disc interface after the friction test. It is believed that each layer may differ in their functionality, though they both collectively contribute to overall performance of the whole tribofilm. The chemical composition of each layer is correlated to different response of ionic components under the intense effect of sheared stress. It is evidenced by EDS mapping that the Na-rich layer (I) is the foundation of the bi-layered structure. During mechanical contact, exo-electron emission is acknowledged and often regarded as an activation energy source favoring tribochemical reactions ${ }^{26}$. In addition, as the wear test was conducted at elevated temperature, oxidation sequence should be taken into account where outward electron transfer plays an important role in redox reaction on the interface ${ }^{27}$. As a result, an interface with high electron potential is established which energetically attracts cationic moieties in the lubricant 
melt. Na cations with relatively small radius and superior mobility, preferably anchor themselves on the disc interface and eventually form a thin layer of $\sim 10-20 \mathrm{~nm}$. The formation of anti-oxidation nanolayer was facilitated by both shearing stress and oxidation sequences, although potential reaction between sodium and iron oxide can be also expected at elevated temperature. On one hand, the base layer can be considered as an impermeable barrier that possibly terminates the route for oxidants adsorption (gaseous oxygen and probably free $\mathrm{O}^{2-}$ ) on the steel substrate. On the other hand, to an extreme, the highly mobile $\mathrm{Na}$ can migrate into the interstitial sites of the scale matrices and consequently restrict the migrant $\mathrm{Fe}^{2+}$ from diffusing toward the interface. Such a thin film with capacity in isolating reagents, can ultimately suppress the scale development which is intrinsically problematic at high temperature oxidation. In an extent, anti-wear capacity of the tribofilm can benefit from the antioxidation nanolayer since the oxidation of iron oxides debris to form hard and abrasive heamatite potentially amplifies wear severity.

Since the observation of B distribution by X-ray technique faces inherent challenges due to low atomic number of the element, HAADF imaging was used as an alternative approach. With high sensitive towards Z-number differences reflected by image contrast, the technique is capable of distinguishing elements with great $\mathrm{Z}$ disparity and providing concentration gradient. It is evidenced by X-ray spectra and EELS analysis that the melt lubricant is comprised of $\mathrm{B}, \mathrm{O}$ and $\mathrm{Na}$ with increasing atomic number $Z=5,8$ and 11, respectively. From HAADF image of the disc interface (Figure 12), a stark contrast between oxide base and the overlying glassy film can be easily discriminated as the substrate appears much brighter than the remaining region. These arise from the presence of $\mathrm{Fe}$ in the oxide scale which is much heavier $(\mathrm{Z}=26)$ than any other melt constitutions. Within the tribofilm, the dual layers exhibit comparatively different contrast as the upper layer is darker than its underlying counterpart. This explicitly points out the inclusion of light element in chemical makeup with greater 
concentration compared to other areas. In accordance to EDS analysis, the base layer is assigned to be Na-rich and the whole bi-layered tribofilm is considerably deprived of O. Furthermore, since B is the lightest element among the tribosystem, it turns plausible that the upper layer is mainly compounded of vitreous boron oxides. The glassy layer is then characterized by highly-concentrated $\mathrm{B}$ and $\mathrm{O}$ depletion which is strongly indicative of polymerization occurred under the effect of stressed shearing. In principle, $\mathrm{B}$ exists in its most stable form when screened by $\mathrm{O}$ atoms in inorganic boron oxides ${ }^{28}$ thus the polymerization can be triggered through formation of bonding-oxygens. An illustrative schematic of the tribologically-driven process is proposed in Figure 13. The self-adaptation behavior can be considered as a smart response of the tribofilm to alleviate the direct impact imposed on the substrate. The upperlayer thus dominates the anti-wear capacity due to its high degree of condensation featured by increasing cohesive strength of the tribofilm bulk. Besides, friction reduction capability of the tribofilm can be associated to the amorphous nature of the bi-layered tribofilm. The $\mathrm{O}$ depletion not only provides reasoning evidence about the possible polymerization in the tribofilm, but also underlines the anti-oxidation potentials which the lubricant melt can deliver on heated rubbing interface.

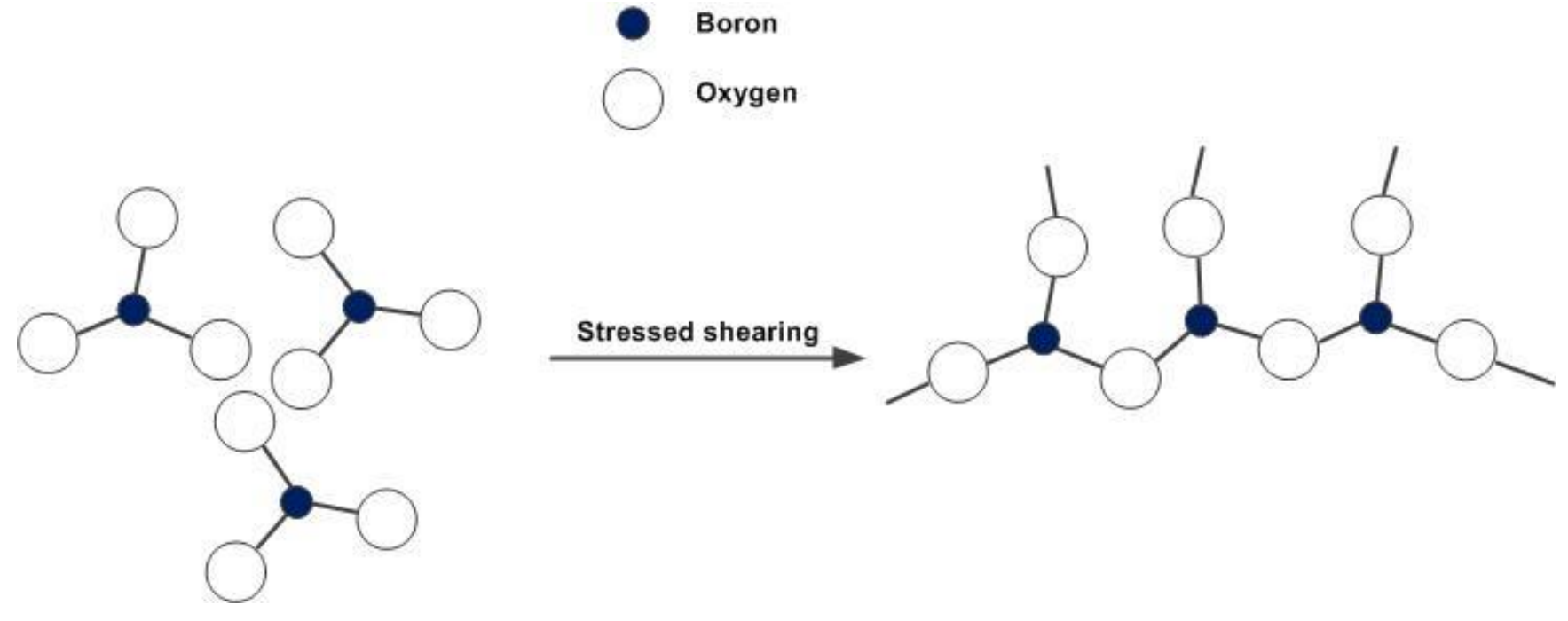

Figure 13: Simplified schematic of tribologically-induced polymerization in vitreous borate tribofilm. 
On the opposing contact area, interfacial structure appears complex with the formation of ultra-fine grained iron oxides beneath a boundary thin film. While the overlying film mainly involves lubricant chemistry, the induced nano-grain layer with unique characteristics can dominate the microstructural properties of the rubbing surface. Ultrafine-grained materials have been prevalently known for their unusual mechanical features including high yield strength, excellent impact toughness and good fatigue strength $^{29-31}$. Superior mechanical characteristics are predominantly associated to the substantial boundaries density within the microstructure beside grain size dependence. Herein, the surficial region of nano-grained oxides (average diameter of $50-150 \mathrm{~nm}$ ) can significantly enhance the mechanical strength of the rubbing interface and consequently increase its wear resistance ${ }^{32-33}$. As shown previously, the astonishing smoothness observed can be attributed to the improved wear resistance when asperities contacts are ultimately minimized under such surface quality. The nanoscale grains neatly arrange themselves on the interface within a refinement range of $\sim 200-300 \mathrm{~nm}$ without being scattered outwards. During the mechanical contact, the ultrafine-grained layer was persistently in contact with the overlying glassy film and the bi-layered tribofilm on the disc interface. These vitreous films can play a certain role in confining the microstructural region. Apart from reinforcement capacity, nano-size grains are also characterized by high boundary diffusion coefficient ${ }^{34-35}$ which can contribute to the complex chemistry of the overlying film. The film is chemically made up with expected melt elements $(\mathrm{B}, \mathrm{O}, \mathrm{Na})$ with $\mathrm{Fe}$ and $\mathrm{C}$ from the steel. High temperature oxidation of steel invariably induces continuous outward diffusion of Fe and decarburization which require consideration. TEM micrograph of the steel substrate extracted from the ball scar displays continuous voids along the scale/steel base interface (Figure 14). The void formation could be associated to the relatively high pressure of carbon-bearing gases generated during steel oxidation which has been previously 
acknowledged ${ }^{27,36}$. The decarburization process corresponds to competitive oxidation of solute [C] species in steel base which produces mixture of carbonaceous gases detailed in the following route:

$$
[\mathrm{C}]+\mathrm{FeO} \rightarrow \mathrm{Fe}+\mathrm{CO} / \mathrm{CO}_{2}(\mathrm{~g})
$$

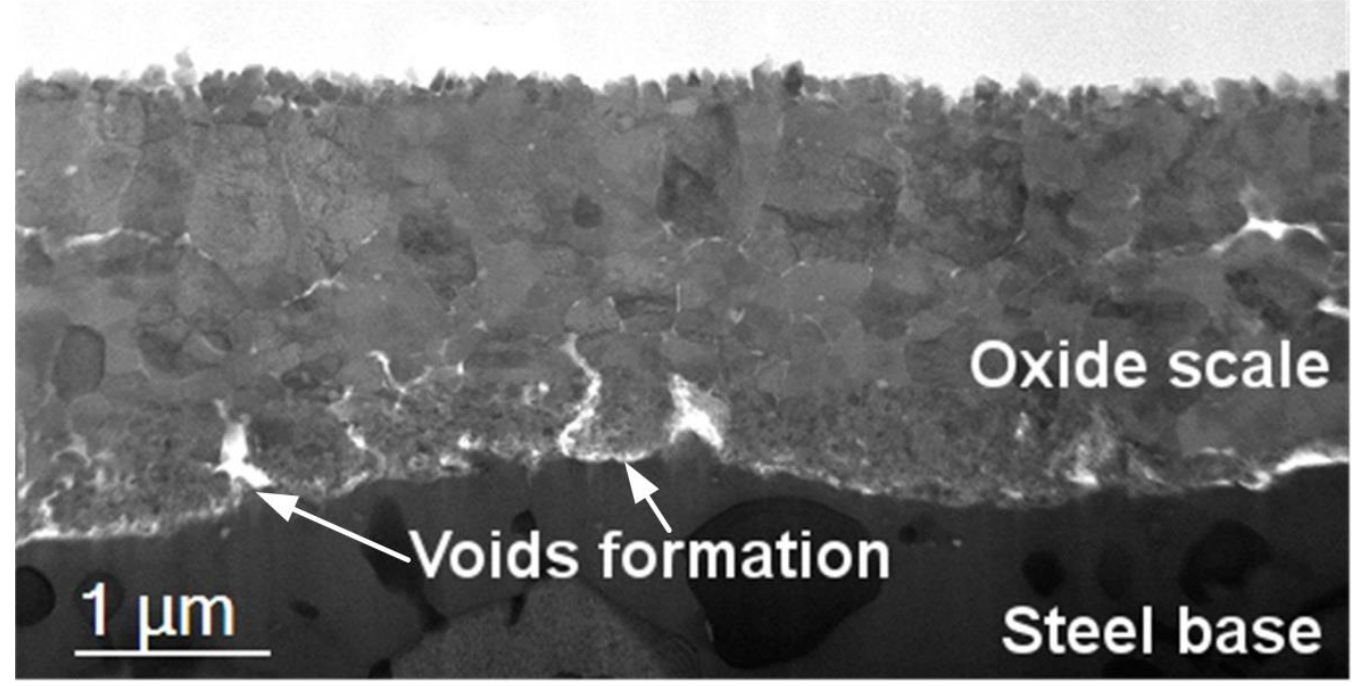

Figure 14: BF image of cross-sectional scale/steel interface of GCr15 ball after friction test.

As the GCr15 ball consists of approximately $1 \% \mathrm{C}$, decarburization is reasonably likely ${ }^{37}$. The gaseous mixture tends to escape the steel substrate via grain boundary diffusion in the scale bulk ${ }^{36}$. Molecular diffusivity elevates markedly when the carbon-bearing gases approach the nano-grained layer which potentially paves a pathway to carbon inclusion in the overlying film composition. The migrant gases are confined on the interface boundary during the sliding process since the ball experiences continuous engagement against the rotating disc. Under the effect of constant tribological exposure and tremendous heat, complex reaction can take place which eventually transforms carbonbearing gases into amorphous carbon. The amorphous carbon is considered intrinsic, given that thin lamellar was constantly kept in high vacuum condition of the SEM-FIB until TEM examination neglecting the possibilities of pollution. Outward diffusion of iron through interstitial sites is considered 
rate-determining stage in scaling process when the oxide scale thickens ${ }^{27}$. Again, the interface nanograins can accelerate $\mathrm{Fe}$ diffusion and subsequently incorporate it into the boundary film. With variable coordination number, $\mathrm{Fe}$ has been known to increase the network connectivity of the glassy film which consequently strengthens the interfacial structure ${ }^{38}$. As demonstrated before, resolved EELS spectra indicate dominant vitreous boron oxide within the film composition where complete conversion from tetrahedral $\mathrm{BO}_{4}$ to trigonal planar $\mathrm{BO}_{3}$ can be observed.

In the present study, detailed characterizations were conducted out on both steel counterbodies to produce a complete scheme of the contact interfaces. Both tribological factors and high temperature oxidation sequences were considered in respect to the formation mechanism of interface integrity beside the nature of melt lubricant. The bi-layered boundary film generated on the disc interface is the core element for the excellent lubrication. The base layer is rich in $\mathrm{Na}^{+}$, predominantly accounted as anti-oxidation insulator while tribologically-induced polymerization of the vitreous boron glass in upper counterpart substantially benefits anti-wear characteristic. The polymerization of vitreous layer presents smart self-adaptation in response to stressed shearing excitation which results in superior wear resistance of the tribolayer. In addition, the condensation reaction also leads to $\mathrm{O}$ depletion on the interface promoting oxidation resistance yield. Apart from friction reduction, the synergy between wear resistance and oxidation resistance underlines the great potentials of the bi-layered tribofilm, especially in mechanical contact at elevated temperature. On the opposing ball scar, the contact surface is characterized by an interfacial film overlying ultrafine-grained oxides sublayer. Surface properties are dominated by the nanograined layer by its superior yield strength and toughness which consequently enhances wear resistance. It is suggested that the nano-grains refinement was originated from the evolution of initial wear debris of the ball under the effects of shearing and opposing glassy tribofilm. In addition, elevated diffusivity of high-density boundaries may contribute to the formation mechanism 
of chemically complex film. The integrity of tribologically- and oxidation-induced interface eventually attributes to the exceptional performance of the lubricant melt.

Elevated temperature imposed various obstacles in observing and understanding of the boundary tribofilm. The highly kinetic aftermath has great chances in distorting the actual state of the interface structure, especially the tribochemical film. In the current study, steel components were retrieved immediately after friction test, thus the interfaces were presumably "freezing" until further characterization. In fact, the obtained bi-layered tribofilm appears well-preserved despite minor indication of diffusion pattern which is around $200 \mathrm{~nm}$ above. However, the observation is also attributed to formation highly-concentrated B with characteristic contrast of the upper tribolayer. The fact that produced lamellars were stored in high vacuum condition makes interfacial observation more credible since the tribochemical film appears vulnerable to oxidation. Besides, one possible approach

to mitigate beam damage is probing the lamellars at liquid nitrogen temperature which can be considered in the future studies.

\section{Conclusions}

Tribological properties of inorganic sodium borate were investigated by mean of wear test at elevated temperature. It has been found that the lubricant melt exhibit remarkable lubrication performance regarding friction reduction, wear inhibition and oxidation resistance compared to unlubricated condition. Interface characterizations have been conducted on both steel parts unfolding the formation of complex interfaces in microstructural and chemical term. A multi-functional bi-layered tribofilm was generated on the disc interface governing oxidation resistance and wear inhibition. Self-adaptation by means of polymerization is attributed to excellent anti-wear characteristic of the upper glassy layer while the underlying Na-rich nanolayer is accounted for anti-oxidation capacity. On the opposing ball, a hierarchical interface composing of glassy film and interface-controlled nanograined sublayer were 
illustrated. The emergence of ultrafine grained region significantly increases interfacial strength and wear resistance. Both tribological exposure and high-temperature oxidation sequence are considered as contributing factors to the formation mechanism of the chemically complex boundary. By employing Energy Dispersive Spectroscopy mapping, EELS analysis coupled with HAADF imaging technique, relative distribution of melt elements were justified, in particular B. The current study reveals the prospects of melt lubrication for improving tribological performance of steel contacts at elevated temperatures.

\section{ASSOCIATED CONTENT}

\section{Supporting Information}

The Supporting Information is available free of charge: Supporting Information (word).

Schematic of High Temperature Microscopy apparatus.

$>$ Temperature evolution of steel components during the High-Temperature friction test.

$>$ X-ray Powder Diffraction pattern of collected wear debris from unlubricated test.

SEM images of thin lamellar extracted from GCr15 ball and MC disc after FIB milling.

\section{AUTHOR INFORMATION}

\section{Corresponding Authors}

*Email: ktieu@uow.edu.au, shanhong@uow.edu.au

\section{ACKNOWLEDGMENT}

The study is funded by Australian Research Council Discovery Project (DP) 150103718. Electron Microscopy Center facilities (EMC-UOW) including JOEL JSM-6940LV (SEM), FEI Helios-G3 CX (SEM-FIB) and JOEL ARM-200F (STEM) were used in this study. 


\section{REFERENCES}

(1) Erdemir, A. A Crystal-Chemical Approach to Lubrication by Solid Oxides. Tribol. Lett. 2000, 8, 97-102.

(2) Wan, S.; Tieu, A. K.; Xia, Y.; Zhu, H.; Tran, B. H.; Cui, S. An Overview of Inorganic Polymer as Potential Lubricant Additive for High Temperature Tribology. Tribol. Int. 2016, 102, 620-635.

(3) Tieu, A. K.; Kong, N.; Wan, S.; Zhu, H.; Zhu, Q.; Mitchell, D. R. G.; Kong, C. The Influence of Alkali Metal Polyphosphate on The Tribological Properties of Heavily Load Steel on Steel Contacts at Elevated Temperatures. Adv. Mater. Interfaces 2015, 2, 1-14.

(4) Wan, S.; Tieu, A. K.; Zhu, Q.; Zhu, H.; Cui, S.; Mitchell, D. R. G.; Kong, C.; Cowie, B.; Denmen, J. A.; Liu, R. Chemical Nature of Alkaline Polyphosphate Boundary Film at Heated Rubbing Surfaces. Sci. Rep. 2016, 6, 26008.

(5) Shah, F. U.; Glavatskih, S.; Antzutkin, O. N. Boron in Tribology: From Borates to Ionic Liquids. Tribol. Lett. 2013, 51, 281-301.

(6) Konijnendijk, W. L.; Stevels, J. M. The Structure of Borate Glasses Studied by Raman Scattering. J. Non-Cryst. Solids 1975, 18, 307-331.

(7) Farajpour, T.; Bayat, Y.; Abdollahi, M.; Keshavarz, H. Effect of Borax on The Thermal and Mechanical Properties of Ethylene-Propylene-Dieneterpolymer Rubber-Based Heat Insulator. J. Appl. Polym. Sci. 2015, 465, 41936.

(8) Waclawska, I. Thermal Decomposition of Borax. J. Therm. Anal. 1995, 43, 261-269. 
(9) Pique, B.; Bouchard, P.-O.; Montmitonnet, P.; Picard, M. Mechanical Behavior of Iron Oxide Scale: Experimental and Numerical Study. Wear 2006, 260, 231-242.

(10) Otten, M. T. High-Angle Annular Dark-Field Imaging on a TEM/STEM System. J. Electron Microsc. Tech. 1991, 17, 221-230.

(11) Araujo, D.; Alegre, M. P.; Pinero, J. C.; Fiori, A.; Bustarret, E.; Jomard, F. Boron Concentration Profiling by High Angle Annular Dark Field-Scanning Transmission Electron Microscopy in Homoepitaxial Doped Diamond Layers. Appl. Phys. Lett. 2013, 103, 042104.

(12) Utsunomiya, S.; Ewing, R. C. Application of High-Angle Annular Dark Field Scanning Transmission Electron Microscopy, Scanning Transmission Electron Microscopy-Energy Dispersive X-ray Spectrometry, and Energy-Filtered Transmission Electron Microscopy to The Characterization of Nanoparticles in The Environment. Environ. Sci. Technol. 2003, 37, 786-791.

(13) Inman, I. A.; Datta, S.; Du, H. L.; Burnell-Gray, J. S.; Luo, Q. Microscopy of Glazed Layers Formed During High Temperature Sliding Wear at $750^{\circ} \mathrm{C}$. Wear 2003, 254, 461-467.

(14) Stott, F. H.; Lin, D. S.; Wood, G. C. The Structure and Mechanism of Formation of The "Glaze" Oxide Layers Produced on Nickel-Based Alloys During Wear at High Temperatures. Corros. Sci. 1973, $13,449-469$.

(15) Lundberg, S.-E.; Gustafsson, T. The Influence of Rolling Temperature on Roll Wear, Investigated in A New High Temperature Test Rig. J. Mater. Process. Technol. 1994 42, 239-291.

(16) Shartsis, L.; Capps, W.; Spinner, S. Viscosity and Electrical Resistivity of Molten Alkali Borates. J. Am. Ceram. Soc. 1953, 36, 319-326. 
(17) Mitchell, D. R. G.; Schaffer, B. Scripting-Customised Microscopy Tools for Digital Micrograph $^{\mathrm{TM}}$. Ultramicroscopy 2005, 103, 319-332.

(18) Sauer, H.; Brydson, R.; Rowley, P. N.; Engel, W.; Thomas, J. M. Determination of Coordinations and Coordination-Specific Site Occupancies by Electron Energy-Loss Spectroscopy: An Investigation of Boron-Oxygen Compounds. Ultramicroscopy 1993, 49, 198-209.

(19) Garvie, L. A. J.; Craven, A. J. Parallel Electron Energy-Loss Spectroscopy (PEELS) Study of B in Minerals: The Electron Energy-Loss Near-Edge Structure (ELNES) of The B K Edge. Am. Mineral. 1995, 80, 1132-1144.

(20) Yang, G.; Mobus, G.; Hand, R. J. Cerium and Boron Chemistry in Doped Borosilicate Glasses Examined by EELS. Micron 2006, 37, 433-441.

(21) Cheng, S.; Yang, G.; Zhao, Y.; Peng, M.; Skibsted, J.; Yue, Y. Quantification of Boron Speciation In Alkali Borosilicate Glasses by Electron Energy Loss Spectroscopy. Sci. Rep. 2015, 5, 17526.

(22) Murooka, Y.; Tanaka, N.; Hirono, S.; Hibino, M. Electron Energy-Loss Spectroscopy of Carbon Films Prepared by Electron-Cyclotron-Resonance Plasma Sputtering. Mater. Trans. 2002, 43, 20922096.

(23) Havenbergh, K. V.; Turner, S.; Driesen, K.; Bridel, J.-S.; Tendeloo, G. V. Solid-Electrolyte Interphase Evolution of Carbon-Coated Silicon Nanoparticles for Lithium-Ion Batteries Monitored by Transmission Electron Microscopy and Impedance Spectroscopy. Energy Technol. 2015, 3, 699-708.

(24) Mackenzie, J. D. The Physical Chemistry of Simple Molten Glasses. Chem. Rev. 1956, 56, 455470. 
(25) Ehrt, D.; Keding, R. Electrical Conductivity and Viscosity of Borosilicate Glasses and Melts. Phys. Chem. Glasses 2009, 50, 165-171.

(26) Minami, I. Ionic Liquids in Tribology. Molecules 2009, 14, 2286-2305.

(27) Young, D. J., High Temperature Oxidation and Corrosion of Metals. Elsevier, 2016.

(28) Lee, S. K.; Eng, P. J.; Mao, H.-K.; Meng, Y.; Newville, M.; Hu, M. Y.; Shu, J. Probing of Bonding Changes in $\mathrm{B}_{2} \mathrm{O}_{3}$ Glasses at High Pressure with Inelastic X-Ray Scattering. Nat. Mater. 2005, $4,851-854$.

(29) Leinonen, J. I. Superior Properties of Ultra-Fine-Grained Steels. Acta. Polytech. 2004, 44, 37-40.

(30) Valiev, R. Z. Structure and Mechanical Properties of Ultrafine-Grained Metals. Mater. Sci. Eng. A 1997, A234-236, 59-66.

(31) Valiev, R. Z.; Korznikov, A. V.; Mulyukov, R. R. Structure and Properties of Ultrafine-Grained Materials Produced by Severe Plastic Deformation. Mater. Sci. Eng. A 1993, A168, 141-148.

(32) Nie, X.; Zhang, P.; Weiner, A. M.; Cheng, Y.-T. Nanoscale Wear and Machining Behavior of Nanolayer Interfaces. Nanoletters 2005, 5, 1992-1996.

(33) Shakhvorostov, D.; Gleising, B.; Buscher, R.; Dudzinski, W.; Fischer, A.; Scherge, M. Microstructure of Tribologically Induced Nanolayers Produced at Ultra-Low Wear Rates. Wear 2007, $263,1259-1265$.

(34) Divinski, S.; Wilde, G. Diffusion in Ultrafine Grained Materials. Mater. Sci. Forum 2008, 584$586,1012-1017$. 
(35) Sauvage, X.; Wilde, G.; Divinski, S. V.; Horita, Z.; Valiev, R. Z. Grain Boundaries in Ultrafine Grained Materials Processed by Severe Plastic Deformation. Mater. Sci. Eng. A 2012, 540, 1-12.

(36) Chen, R. Y.; Yuen, W. Y. D. Review of The High-Temperature Oxidation of Iron and Carbon Steels in Air or Oxygen. Oxid. Met. 2003, 59, 433-468.

(37) Malik, A. U.; Whittle, D. P. Oxidation of Fe-C Alloys in The Temperature Range $600-850^{\circ} \mathrm{C}$. Oxid. Met. 1981, 16, 339-353.

(38) Mosey, N. J.; Woo, T. K.; Kasrai, M.; Norton, P. R.; Bancroft, G. M.; Muser, M. H. Interpretation of Experiments on ZDDP Anti-Wear Films Through Pressure-Induced Cross-Linking. Tribol. Lett. 2006, 24, 105-114. 


\section{TOC Graphic}

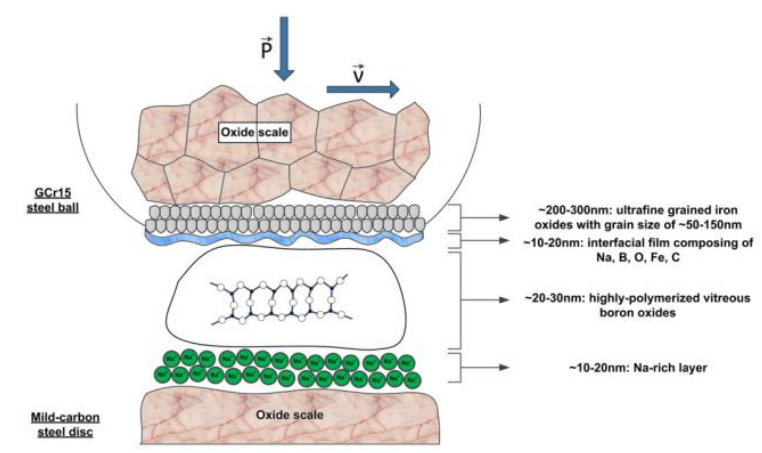

